\title{
HNE-protein adducts formation in different pre-carcinogenic stages of hepatitis in LEC rats
}

\author{
ADRIANA MARQUEZ-QUIÑONES ${ }^{1,2}$, ANA ČIPAK ${ }^{3}$, KAMELIJA ŽARKOVIC $^{4}$, \\ SAMIA FATTEL-FAZENDA ${ }^{2}$, SAUL VILLA-TREVIÑNO ${ }^{2}$, GEORG WAEG $^{5}$, \\ NEVEN ŽARKOVIC ${ }^{3}$, \& FRANÇOISE GUÉRAUD ${ }^{1}$ \\ ${ }^{1}$ INRA-ENVT, UMR 1089-Xénobiotiques, Toulouse, France, ${ }^{2}$ Department of Cell Biology, Center of Research and of Advanced \\ Studies of the Institute Politecnico National, Mexico DF, Mexico, ${ }^{3}$ Division of Molecular Medicine, Rudjer Boskovic Institute, \\ Zagreb, Croatia, ${ }^{4}$ Department of Neuropathology, Clinical Hospital Centre, Zagreb, Croatia, and ${ }^{5}$ Institute of Molecular \\ Biosciences, University of Graz, Graz, Austria
}

(Received date: 16 fune 2009; In revised form date: 1 September 2009)

\begin{abstract}
Lipid peroxidation is highly associated with chronic degenerative diseases such as cancer. 4-hydroxy-2-nonenal is one of the major products of lipid peroxidation. 4-hydroxy-2-nonenal can interact with biomolecules, changing their conformation and activity. This study presents 4-hydroxy-2-nonenal-protein adducts formation in the first stages of Long-Evans Cinnamon rat hepatitis, a well recognized model for oxidative stress-associated hepatocarcinogenesis. 4-hydroxy-2-nonenal-protein adducts appeared in hepatocyte cytoplasm before the beginning of hepatitis and their presence was very strong during hepatitis, while a transient perinuclear expression of 4-hydroxy-2-nonenal-protein adducts was shown mainly at early hepatitis stages. 4-hydroxy-2-nonenal-protein adducts formation correlated to the expression of the tumour marker glutathione S-transferase P-form. These results show that lipid peroxidation modification of proteins might be implicated in the first stages of hepatocyte cancer initiation in Long-Evans Cinnamon rats.
\end{abstract}

Keywords: LEC rats, lipid peroxidation, 4-Hydroxy-2-nonenal, hepatitis, hepatocarcinogenesis

\section{Introduction}

In humans, chronic liver diseases are generated by different causes. Chronic alcohol consumption, viral infections, metabolic dysfunctions, xenobiotic exposition and metal overload are factors associated with hepatitis and liver tumour development. Oxidative stress seems to be a common mechanism involved in all these different hepatitis causes [1-3]. Patients suffering from hepatitis $\mathrm{C}$ manifest hepatic oxidative stress, a condition that is exacerbated by alcohol consumption [4]. 8-Nitroguanine, a marker of DNA oxidation, is highly formed in patients with hepatitis C. Furthermore, some hepatitis C virus (HCV) carriers with normal alanine aminotransferase (ALT) levels in serum have elevated levels of lipid peroxidation products and low levels of reduced glutathione (GSH) in plasma. In these patients, a greater degree of oxidative stress markers correlates with a more severe status of the disease [1].

Carcinogenesis is a complex multi-stage process in which both proliferation and cell death are altered. According to observations made in models of chemical carcinogenesis (mainly in liver) and in epidemiological findings, the process of neoplastic development has been operationally divided into three defined stages: initiation, promotion and progression [5-7]. Initiation follows irreversible changes in the genotype of cells (i.e. mutations in critical genes such as oncogenes and tumour suppressor genes). The promotion stage is characterized by the clonal expansion of

Correspondence: Françoise Guéraud, PhD, Institut National de la Recherche Agronomique, UMR 1089-Xenobiotiques, INRA/ENVT, 180, Chemin de Tournefeuille, BP 3, 31931, Toulouse Cedex 9, France.Tel: (33) 561-28-50-05. Fax: (33) 561-38-52-44. Email: fgueraud@, toulouse.inra.fr 
initiated cells by the induction of cell proliferation and/or inhibition of cell death. This process results in the formation of identifiable focal lesions (pre-neoplastic lesions). Progression involves cellular and molecular changes that occur from the pre-neoplastic to the neoplastic state. This stage is mainly characterized by genetic instability and disruption of chromosome integrity [8]. Each of the carcinogenesis stages can be followed using different molecular markers known as tumour markers. Two well described tumour markers are the gamma-glutamyltranspeptidase (GGT) and the gluthatione-S-transferase type $P$ (GST-P). GGT and GST-P are not expressed in adult rat hepatocytes, but are highly expressed in most of the chemical carcinogenesis models; their induction can be seen in single hepatocytes from 2 or 3 days of the administration of carcinogens and are present until tumour formation. Due to their pattern of expression from the first until the last stages of liver tumour development, GGT and GST-P are actually considered as early tumour markers $[9,10]$.

During the first stages of carcinogenesis, cells acquire a resistant phenotype, by which cells are resistant to physiological mechanism of cell growth regulation and also to cytotoxic environments [11]. Hence, initiated cells might be more able to proliferate and resist to apoptotic physiological stimulus. Initiation stage of liver carcinogenesis is closely related to liver injury and consequent cellular turnover caused by the different aetiologies of hepatitis $[12,13]$. Mechanisms by which hepatocytes are transformed into pre-neoplastic and neoplastic cells are not well understood, but the influence of oxidative stress and lipid peroxidation in these processes becomes more evident.

An accepted model for studying the relationship between oxidative stress and hepatocarcinogenesis is the Long-Evans Cinnamon (LEC) rat model. LEC rats generate spontaneous acute hepatitis, fibrosis and liver tumours as a consequence of an abnormal liver copper $(\mathrm{Cu})$ accumulation and subsequent oxidative stress [14]. This rat strain shows chronic liver damage, hepatocyte death and regeneration, at the promotion stage of carcinogenesis. Such a natural history of hepatocellular carcinoma (HCC) development in LEC rats is similar to that of human HCC.

Hepatocarcinogenesis in LEC rats is related to liver $\mathrm{Cu}$ and iron accumulation, since, in rats fed a low $\mathrm{Cu}$ and iron diet or treated with copper-chelating agents, pre-neoplastic lesions almost disappear $[15,16]$. Copper-associated liver injury is regarded as resulting ultimately from oxidative stress. Lipid peroxidation products like 4-hydroxynonenal (HNE) and malondialdehyde (MDA), which are genotoxic and cytotoxic compounds, may be implicated in hepatocarcinogenesis initiation in LEC rats. Increased mutagenic exocyclic DNA adducts were observed in the liver of LEC rats [17]. These adducts come from the addition of lipid peroxidation products to DNA [18]. However, little is known about the relation between HNEprotein adducts formation in early liver cancer initiation. In this work, we studied the HNE-protein adducts formation in the early stages of LEC rat hepatocarcinogenesis process and we compared $\mathrm{HNE}$-protein adducts formation between LEC rats at the stage of acute hepatitis and LEC rats treated with D-penicillamine, a copper chelating agent. HNE-modified proteins were present from the beginning of hepatitis, which corresponded also to the cancer initiation step in this rat strain. Our results stress the importance of HNE and lipid peroxidation in cancer and liver diseases.

\section{Methods}

\section{Animals and treatments}

LEC rats were bred in our Institution animal facility from rats kindly given by Dr Matsumoto from Tokushima University (Japan). All procedures and animal care was done according to our local Committee on Ethics of Animal Experiments. Male LEC rats were maintained in metabolic cages from 6 weeks old until sacrifice at different hepatitis stages. For the D-penicillamine-treated rat group, six LEC rats were given D-penicillamine in drinking water $(100 \mathrm{mg} / \mathrm{kg} /$ day $)$ for 6 weeks until sacrifice at 13 weeks old. D-penicillamine (Sigma, Saint-Quentin Fallavier, France) concentration was adjusted every 3 days according to water consumption and rat weight.

\section{Tissue preparation}

Rats were sacrificed by exsanguination under ether anaesthesia. Blood was taken from the aorta vein for plasma separation. The liver was excised and washed in physiological saline solution. For histological examination, liver samples were fixed in $4 \%$ buffered formaldehyde and embedded in paraffin. For $\gamma$-glutamyl-transpeptidase (GGT) activity histochemistry, liver fractions were frozen by immersion in liquid nitrogen-cooled 2-methylbutane and stored at $-80^{\circ} \mathrm{C}$.

\section{Hepatitis markers determination in plasma}

Aspartate aminotransferase (AST), alanine aminotransferase (ALT) activities and total bilirubin (t-bilirubin) levels in plasma were determined by standard photometrical analyses at the Functional Exploration Platform at Toulouse Genopôle (Toulouse, France).

8-Isoprostaglandine $F_{2 a}\left(8-I s o P G F_{2 a}\right)$ urine determination by competitive enzymatic immunoassay (EIA)

(8-IsoPGF $2 a$ ) was determined by EIA according to Pradelles et al. [19] and Wang et al. [20]. A calibration 
curve from $7.2 \mathrm{pg} / \mathrm{ml}$ to $1 \mathrm{ng} / \mathrm{ml}$ was used. Samples were assayed in duplicate with a 1:20 dilution. After an incubation period of $18 \mathrm{~h}$ with the specific antibody, tracer (8-IsoPGF Pa $_{2 \alpha}$ bound to acetylcholine esterase) is added for another incubation period during $4 \mathrm{~h}$. After a washing step, the product of the enzymatic reaction of the tracer is determined spectrophotometrically at $414 \mathrm{~nm}$ using a plate reader (Multiskan Ascent, Thermo Labsystem, Cergy Pontoise, France). The colour intensity is proportional to the amount of 8-IsoPGF ${ }_{2 \alpha}$ tracer bound to the well, which is inversely proportional to the amount of free 8-IsoPGF ${ }_{2 \alpha}$ present in the well during the incubation. All results were expressed on the basis of $24 \mathrm{~h}$ excretion.

Immunohistochemistry of glutathione S-transferase, placental form (GST-P)

Deparaffinized sections were blocked for $1 \mathrm{~h}$ in $0.1 \%$ $\mathrm{H}_{2} \mathrm{O}_{2}$ in phosphate-buffered saline (PBS), $\mathrm{pH}$ 7.4. Subsequently, they were incubated overnight with commercial monoclonal antibodies specific to GST-P (DakoCytomation, Glostrup, Denmark) diluted 50times in blocking buffer. After washing with PBS, the primary antibody was detected using an avidin-biotin complex immunoperoxidase technique (Zymed Laboratories, Inc., Carlsbad, CA). Slides were counterstained with haematoxyline and observed in light microscopy.

\section{Immunohistochemistry of 4-hydroxynonenal (HNE)}

Immunohistochemistry for HNE-modified proteins was carried on formalin-fixed paraffin embedded liver tissue samples using monoclonal antibodies obtained from culture medium of the clone 'HNE 1g4', produced by a fusion of $\mathrm{Sp} 2-\mathrm{Ag} 8$ myeloma cells with B-cells of a BALB-c mouse immunized with HNEmodified keyhole limpet haemocyanine. The antibody is specific for the HNE-histidine epitope in HNEprotein (peptide) conjugates and gives only $5 \%$ crossreactivity with $\mathrm{HNE}$-lysine and $4 \%$ with $\mathrm{HNE}$-cysteine $[21,22]$. This monoclonal antibody was proven to be particularly reliable for HNE-immunohistochemistry of various human and animal tissues fixed by formalin [23-26].

Immunohistochemistry was done in a three step procedure as described before using LSAB kit (DAKO, Denmark). In order to diminish the in situ formation of $\mathrm{HNE}$, slides were incubated with $\mathrm{H}_{2} \mathrm{O}_{2}$ as substrate for peroxidase only after antibodies attachment. Hence, deparaffinized sections were incubated in methanol for 2 min then they were washed in PBS three times for 5 min each. Subsequently, slides were incubated overnight with monoclonal antibodies specific to HNEhistidine adducts diluted (1:5) in $1 \%$ bovine serum albumin (BSA) in PBS. After washing with PBS, slides were incubated with $3 \% \mathrm{H}_{2} \mathrm{O}_{2}$ in PBS for $15 \mathrm{~min}$ in the dark. Then, slides were washed in TBS three times for $5 \mathrm{~min}$. Subsequently the primary antibody was detected using a Dako LSAB2 avidin-biotin complex immunoperoxidase system (DakoCytomation). Slides were counterstained with haematoxyline and observed with a light microscope. Liver tissue slides were in parallel stained also for immunofluorescence analysis of the sub-cellular distribution of the HNE-protein adducts using confocal microscopy. The same monoclonal antibodies specific for the HNE-histidine adducts were used after dilution (1:10) in PBS with $1 \%$ BSA. The slides were washed in PBS three times for $5 \mathrm{~min}$. Subsequently the primary antibody was detected using a CY3 labelled antibody (Sigma) $(1: 100)$ in $1 \%$ BSA diluted in PBS. Slides were counterstained with DAPI and observed with a confocal microscope (Leica TCS SP2 AOBS). Histology of the liver specimens was done as qualitative morphological analysis carried by an experienced pathologist, without prior knowledge of the study groups.

Histological detection of gamma-glutamyl transpeptidase (GGT) positive hepatocytes

GGT activity was detected in frozen liver histological sections according to Rutenburg et al. [27]. Representative $5 \mu \mathrm{m}$ thick sections from 2-methylbutane-protected frozen liver slices were obtained with a cryostat at $-15^{\circ} \mathrm{C}$. Slides were fixed in $96 \%$ ethanol for $5 \mathrm{~min}$ at $-20^{\circ} \mathrm{C}$. Slides were then incubated for $20 \mathrm{~min}$ at room temperature in a reaction buffer containing 125 $\mu \mathrm{g} / \mathrm{ml}$ gamma-glutamyl-1-4-methoxy-2-nafthylamide (GMNA), $0.5 \mathrm{mg} / \mathrm{ml}$ glycil-glycine and $0.5 \mathrm{mg} / \mathrm{ml}$ fast-blue in $100 \mathrm{mM}$ Tris $\mathrm{pH}$ 7.5. A red precipitate is then formed in GGT positive cells. Slides were then rinsed with distilled water and incubated in $0.1 \mathrm{M}$ cupric sulphate for $5 \mathrm{~min}$ at room temperature. Finally, slides were rinsed with distilled water and air-dried. Slides were counterstained with haematoxyline and observed with a light microscope.

\section{Statistical analyses}

Biochemical data were statistically analysed using the Graph Path PRISM software (version 4, La Jolla, CA). The data are expressed as mean \pm SEM of six rats per group. One-way ANOVA and the Bonferoni's post-hoc tests were used for comparisons between the groups. Two group comparisons were made by tow-tailed student $t$-test. $p$-values $<0.05$ were considered significant.

\section{Results}

\section{Hepatitits markers and histology}

LEC rats suffer a period of acute hepatitis in a no synchronic manner. Rats were therefore classified from normal to strong hepatitis stage according to 
Table I. Biochemical features of LEC rats at different hepatitis stages. Rats were classified according to their disease state.

\begin{tabular}{|c|c|c|c|c|c|}
\hline Group & LEC $6 \mathrm{w}$ & LEC 9w & Slight jaundice & Jaundice & $p$ \\
\hline Age (weeks) & 6 & 9 & $11-13$ & $11-13$ & - \\
\hline $\operatorname{ALT}(\mathrm{U} / \mathrm{l})$ & $62.83 \pm 5.6^{a}$ & $66.7 \pm 3.1^{a}$ & $584.8 \pm 49.1^{b}$ & $1184.0 \pm 140.7^{c}$ & $<0.0001$ \\
\hline $\operatorname{AST}(\mathrm{U} / \mathrm{l})$ & $123.8 \pm 6.2^{a}$ & $95.5 \pm 3.0^{a}$ & $479.0 \pm 59.1^{b}$ & $725.7 \pm 84.9^{c}$ & $<0.0001$ \\
\hline t-bilirubin $(\mu \mathrm{mol} / \mathrm{l})$ & $2.1 \pm 0.73^{a}$ & $1.9 \pm 0.32^{a}$ & $107 \pm 24.4^{b}$ & $369.7 \pm 93.1^{b}$ & $<0.0001$ \\
\hline Liver histology & Normal & $\begin{array}{l}\text { Normal: Slight } \\
\text { hydropic changes }\end{array}$ & $\begin{array}{l}\text { Abnormal: Cholestasis, } \\
\text { presence of micronecrosis } \\
\text { and apoptosis, inflammatory } \\
\text { infiltrates }\end{array}$ & $\begin{array}{l}\text { Abnormal: Necrosis, apoptosis, } \\
\text { inflammation, cholestasis, } \\
\text { nuclear polymorphism, } \\
\text { fat droplets }\end{array}$ & - \\
\hline
\end{tabular}

Values refer to means \pm SEM. $p$-value obtained by one-way ANOVA. Means without a common letter differ as determined by ANOVA and the Bonferroni post-hoc test.

their levels of hepatitis plasmatic markers and histological hepatitis determination (Table I) [28]. Liver structure was strongly altered during hepatitis periods (Figures 1A-D and Table I) with presence of cholestasis, apoptosis (as indicated by arrows in Figure 1) and inflammation for the slight jaundice group and strong inflammation, apoptosis, hepatocytes nuclear polymorphism and flat droplets (steatosis) in faundice group rats.

\section{GGT and GST-P expression in hepatocytes of $L E C$ rats}

GST-P and GGT are two well known tumour markers in liver. In order to know in which moment cancer initiation stage takes place in LEC rats, we analysed these tumour markers expression in the liver of LEC rats in each hepatitis period. Histological determination of GGT activity and GST-P protein presence in
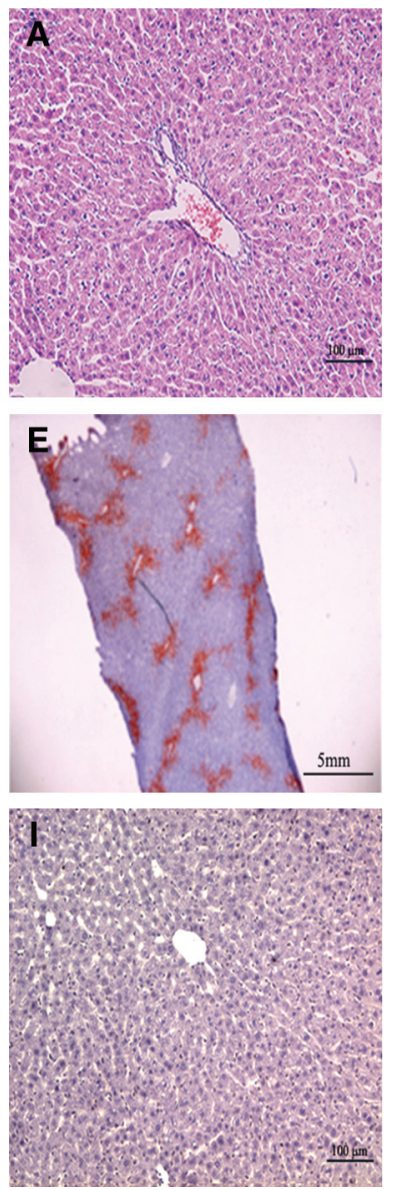
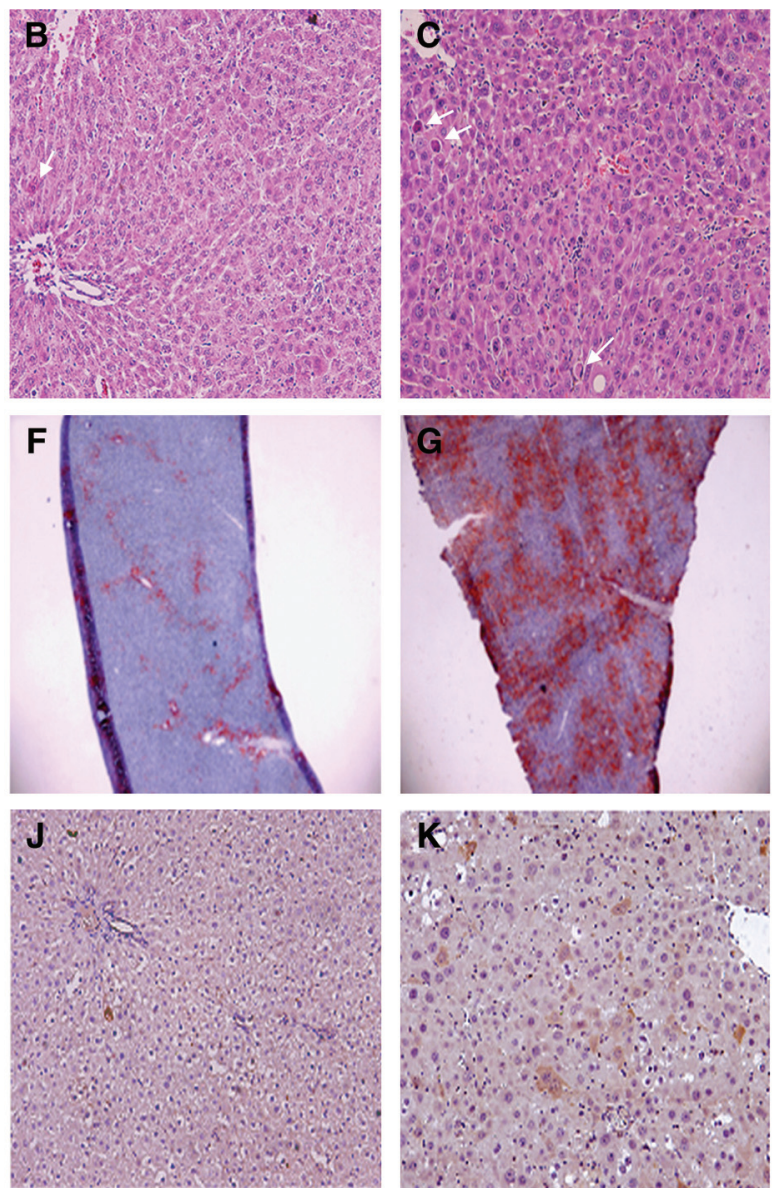
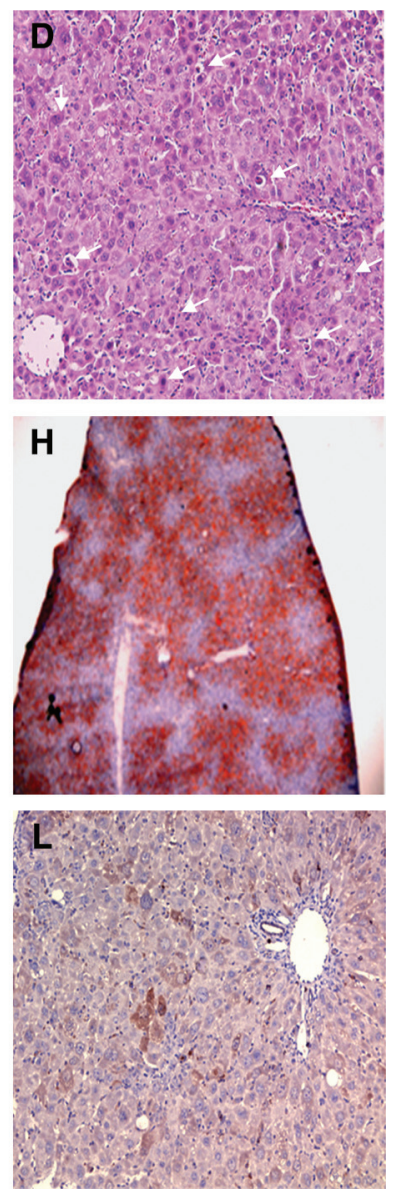

Figure 1. H\&E staining and tumor marker expression in liver of LEC rats at different hepatitis stages. Liver slides were stained with haematoxylin-Eosin (A-D). (E-H) histochemistry of GGT activity; (I-L) GST-P immunohistochemistry. (A) Normal 6w, (B) Normal 9w, (C) Slight jaundice, (D) Faundice, (E) Normal 6w, (F) Normal 9w, (G) Slight jaundice, (H) Faundice; (I) Normal 6w, (J) Normal 9w, (K) Slight Faundice, (L) Faundice. Arrows show apoptotic cells. 

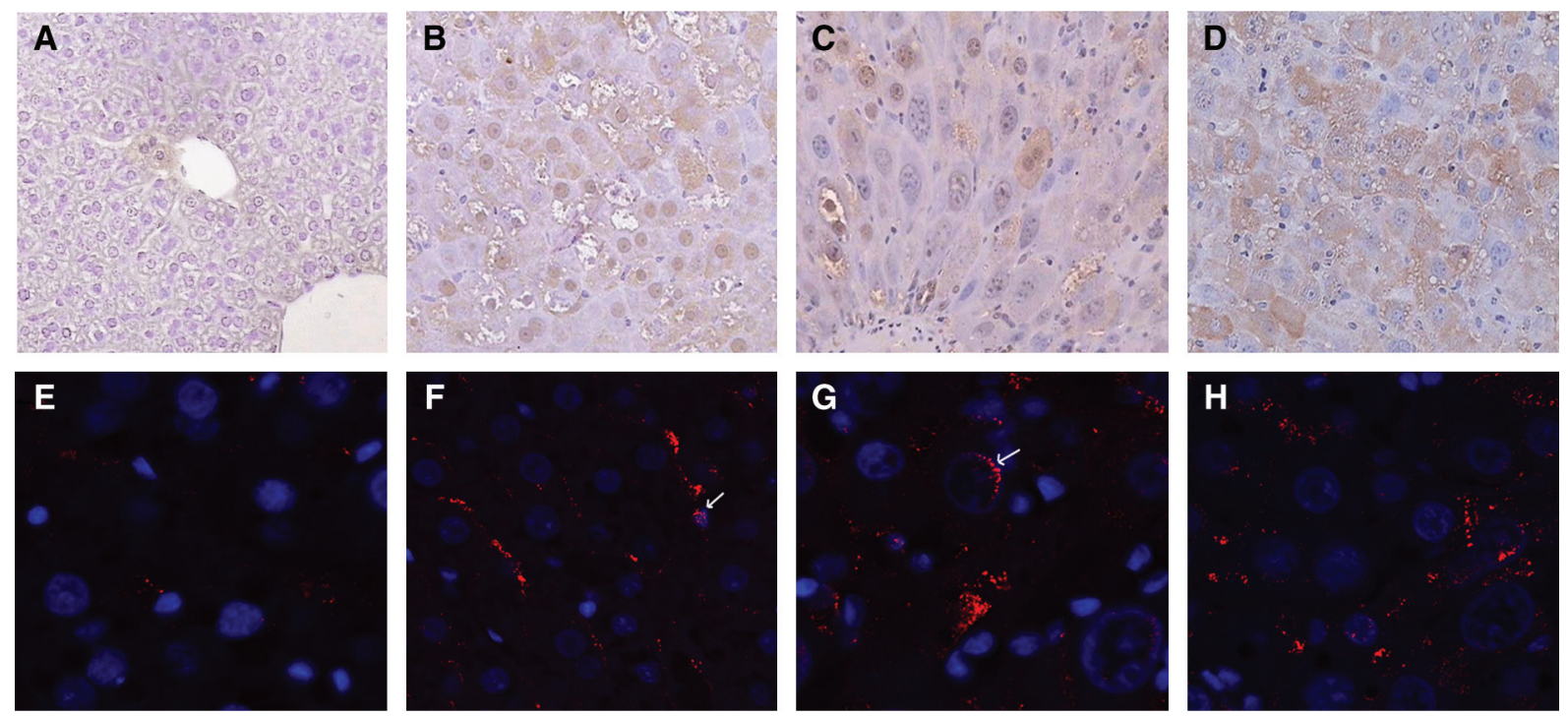

Figure 2. HNE-protein adduction in LEC rat liver at different hepatitis stages: (A-D) Immunohistochemistry for HNE-histidine adducts in liver sections of LEC rats at different hepatitis stages. (A) Normal 6w, (B) Normal 9w, (C) Slight jaundice, (D) Faundice. (E-H) Immunofluorescence for HNE-histidine adducts in liver sections of LEC rats at different hepatitis stages: (E) Normal 6w, (F) Normal 9w, (G) Slight jaundice, $(\mathrm{H})$ Faundice. Arrows show perinuclear localization of HNE-histidine adducts.

liver sections of LEC rats at different hepatitis stages is shown in Figures $1 \mathrm{E}-\mathrm{L}$.

GGT showed a time-dependent increase, which correlated to the state of disease. GGT expression in Normal 6 weeks and Normal 9 weeks rat groups was confined to cells around bile caniliculi (Figures 1E and F). As hepatitis developed, GGT activity was detected in almost all hepatocytes, with no specific topographical distribution (Figures $1 \mathrm{G}$ and $\mathrm{H}$ ).

The evaluation of GST-P protein in hepatocytes by immunohistochemistry showed that GST-P positive hepatocytes appear at the beginning of the hepatitis process (Figure $1 \mathrm{~K}$ ). Cytoplasmic positivity for GST-P expression is present in Slight jaundice and Faundice groups. Interestingly, some groups of GST-P positive hepatocytes were found in faundice groups. Those groups of GST-P positive hepatocytes could be presumed as small foci of 'initiated' cells (Figure 1L). These results indicated that the cancer initiation stage takes place just before the acute phase of hepatitis.

\section{$H N E$-protein adducts in LEC rats hepatocytes}

Copper-associated liver injury is regarded as resulting ultimately from oxidative stress. HNE-protein adducts were visualized by immunohistochemistry (Figure 2). HNE-positive hepatocytes were evaluated in each group of rats, rats from the group Normal 6 weeks presented mild HNE-positivity only occasionally in hepatocytes around blood vessels (Figures 2A and E). Just before hepatitis in the Normal 9 weeks group (Figures $2 \mathrm{~B}$ and $\mathrm{F}$ ), HNE positivity was diffuse, not intensive, but in a lot of hepatocytes. Positivity was both cytoplasmic and nuclear or perinuclear and in some cases nuclear or perinuclear positivity was stronger than the cytoplasmic one. In the diseased rat groups, HNE-modified proteins were also present. In the Slight jaundice group (Figures 2C and G), HNE positivity was mostly cytoplasmic but sometimes perinuclear and sporadically positive picnotic (apoptotic) nuclei were present. During the acute phase of hepatitis, in the faundice group, HNE positivity was diffuse in hepatocyte cytoplasm without any topographic distribution (Figures $2 \mathrm{D}$ and $\mathrm{H}$ ).

Isoprostanes are known products of lipid peroxidation. Among them, 8-IsoPGF ${ }_{2 \alpha}$ has been described as a good marker of oxidative stress and inflammation.

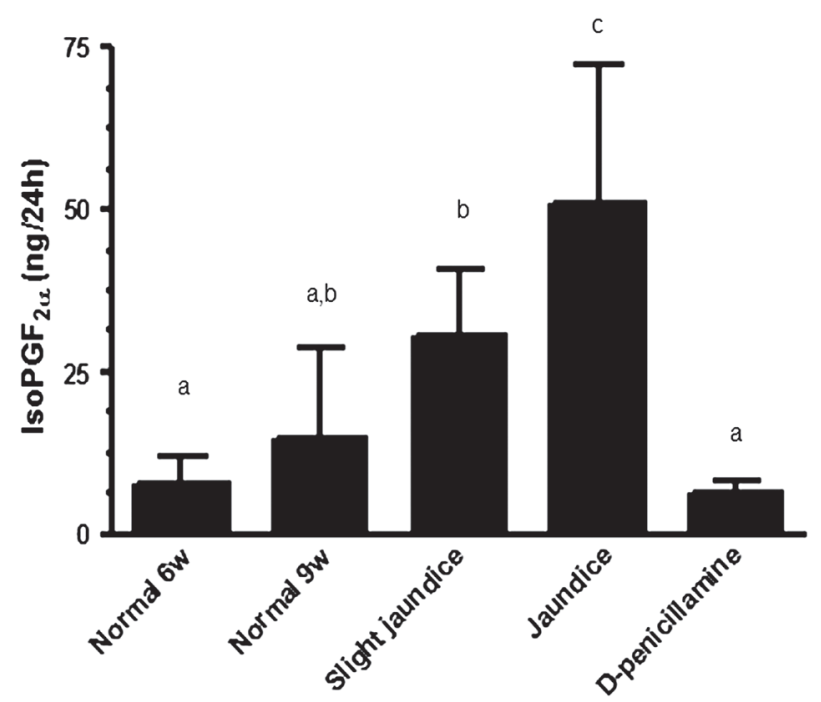

Figure 3. 8-IsoPGF $2 \alpha$ excretion in urine of LEC rats at different hepatitis stages. Urine samples were collected from LEC rats. 8 -IsoPGF ${ }_{2 \alpha}$ was measured by competitive enzymatic immunoassay (EIA). Values refer to means and standard deviations. Means without a common letter differ as determined by ANOVA and the Bonferroni post-hoc test. 

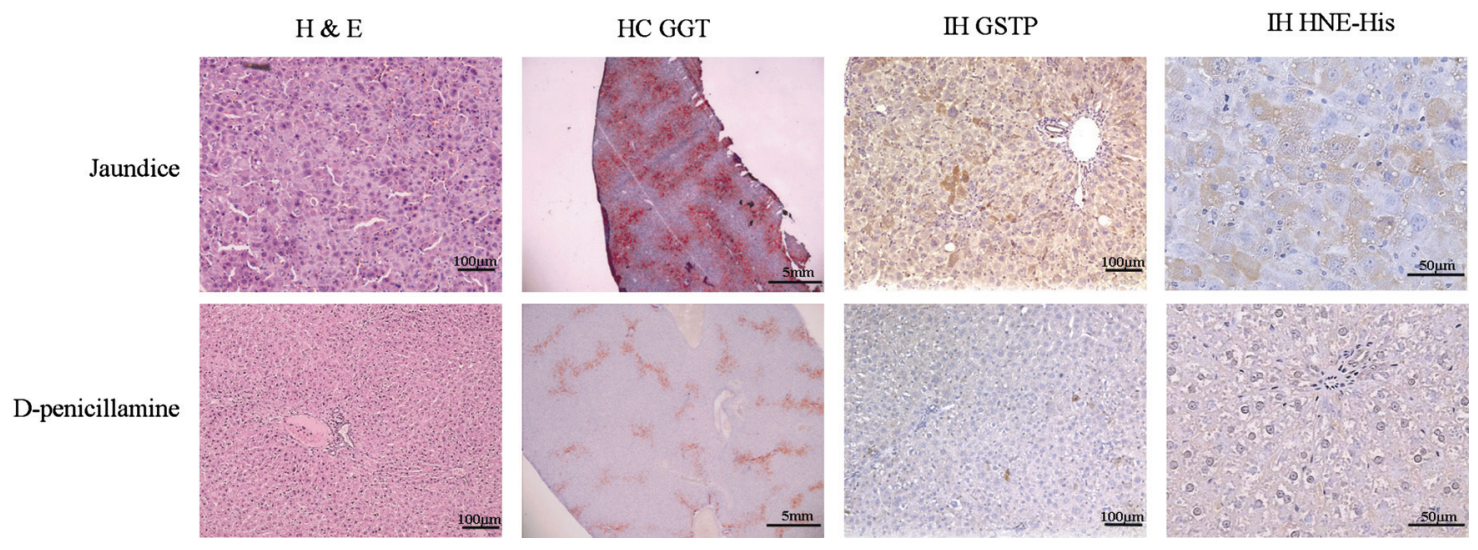

Figure 4. Effect of D-penicillamine on hepatitis development, carcinogenesis initiation and oxidative stress in LEC rats. H\&E: haematoxylinEosin staining; HC GGT: Histochemistry for gamma-glutamyl transpeptidase detection. IH GSTP: Immunohistochemistry for glutathioneS-trasferase detection. IH HNE-His: Immunohistochemistry for HNE-histidine adducts detection.

8-IsoPGF $2 \alpha$ determination in urine showed an increase as hepatitis developed (Figure 3). Levels of 8 -IsoPGF $2 \alpha$ were 6.5-times higher in the faundice group as compared to the Normal 6 weeks group.

\section{Effect of D-penicillamine on hepatitis development and HNE-protein adducts formation}

Figure 4 shows the effect of D-penicillamine administration on hepatitis development in LEC rats. As indicated by hepatitis markers on plasma, D-penicillamine stopped hepatitis development in LEC rats (Table II). D-penicillamine treatment led to rats with normal liver architecture, low levels of GGT activity and no presence of GST-P in hepatocytes (Figure 4). HNE-modified proteins were only seen around portal veins and urinary levels of 8-IsoPGF $2 \alpha$ were diminished by 7.9times in the $D$-penicillamine group of rats compared to the Faundice group.

\section{Discussion}

Lipid peroxidation products such as HNE are nowadays considered as important mediators of oxidative stress-related pathologies. Here we presented the HNE-protein adduct formation in the onset of the hepatocarcinogenesis in LEC rats.

LEC rats have been described to spontaneously suffer acute hepatitis followed by the development of liver tumours. LEC rat hepatitis is not synchronic and takes place around 11-15 weeks old. We and others have previously described the evolution of hepatitis in this rat strain $[28,29]$. In order to have more homogeneous groups, LEC rats were classified according to plasma hepatitis markers rather than age (Table I); the acute phase of hepatitis was characterized by an increase of apoptosis, large nuclei and hepatocytes in mitosis. Liver necrosis and inflammation were found together with an elevation of plasma enzyme activities like ALT, AST and symptoms of jaundice.

Tumour formation in this rat strain follows a natural history similar to the one seen in chemical carcinogenesis in which initiation, promotion and progression stages are followed by the differential expression of proteins, known as tumour markers, in pre-neoplastic and neoplastic lesions [30]. Two of these known tumour markers are GGT and GST-P. Our results showed that both proteins are expressed in hepatocytes at early stages of hepatitis. GGT is an ectoenzyme that is expressed in foetal liver and in bile canaliculi cells; in the adult rat liver, GGT is normally expressed only in the bile canaliculi cells an in the canaliculi membrane face of hepatocytes. GGT activity was detected in higher levels in Normal 6 weeks rats than in the Normal 9 weeks group, even when topographic expression of GGT was normal in both groups. This transitional increase of GGT expression was first described by Jain et al. [31]. They showed an increase

Table II. Biochemical features of D-penicillamine-treated LEC rats and jaundiced LEC rats.

\begin{tabular}{lccc}
\hline Group & Jaundice & D-penicillamine & $p$ \\
\hline Age & $11-13$ & 13 & - \\
ALT $(\mathrm{U} / \mathrm{l})$ & $1184.0 \pm 140.7$ & $45.7 \pm 1.1$ & $<0.0001$ \\
AST $(\mathrm{U} / \mathrm{l})$ & $725.7 \pm 84.9$ & $81.8 \pm 0.9$ & $<0.0001$ \\
t-bilirubin $(\mu \mathrm{mol} / \mathrm{l})$ & $369.7 \pm 93.1$ & $2.3 \pm 0.7$ & $<0.0001$ \\
Liver histology & Abnormal: Necrosis, apoptosis, inflammation, & Normal: Slight hydropic changes & - \\
& cholestasis, nuclear polymorphism, fat droplets & $6.43 \pm 0.75$ & $<0.001$ \\
8-IsoPGF & $50.98 \pm 8.7$ & &
\end{tabular}

Values refer means \pm SEM, $p$-value obtained by two-tailed student $t$-test. 
of GGT mRNA in 4-week-old LEC rats that was then diminished in 8-week-old LEC rats. The over-expression of GGT in hepatocytes has been associated with stress conditions, such as oxidative stress [32] and hepatitis [33], so the increase seen in the liver of the Slight jaundice and faundice rat groups might correspond to the liver disease state and, because of no specific topographical distribution of GGT activity, it is quite difficult to associate GGT expression to the cancer initiation stage in LEC rats.

GST-P is considered as one of the most reliable tumour markers in liver with important effects in cancer-drug resistance [34]. It is not expressed in adult rat hepatocytes and it is expressed in almost $100 \%$ of HCC cells independently of the initiationpromotion stimulus. GST-P expression is poorly related to liver regeneration and it is not induced by electrophilic xenobiotics [35]. Hepatocytes GST-P positive are recognized as population of altered hepatocytes with carcinogenic potential [10,36]. Preneoplastic nodules and HCC in LEC rats are GST-P positive [30]. GST-P expression in hepatocytes at early stages of hepatitis enforces the idea of initiation of carcinogenesis at these stages. GST-P has been shown to be induced as a cellular response to HNE and its expression and activity is closely related to oxidative stress modulation [37]. This suggests the induction of GST-P as an adaptive response to oxidative stress and remarks the importance of lipid peroxidation in cancer initiation.

Lipid peroxidation was clearly related to hepatitis development, as demonstrated both by increased levels of 8-IsoPG ${ }_{2 \alpha}$ in urine and, directly in liver, by formation of HNE-protein adducts. HNE is considered as the major lipid peroxidation product that has been shown to have not only deleterious effects but also an important role in physiological processes as a second messenger of oxidative stress. Its presence is used as a marker of oxidative stress in different tissues and cells during pathophysiological processes [23]. Due to its high reactivity, HNE interacts easily with biomolecules such as nucleic acids and proteins. Proteins are important targets for HNE modification, especially in liver where an active HNE metabolism takes place [38]. Furthermore, HNE-protein adducts can be considered as good markers of lipid peroxidation in liver diseases [39]. HNE-modified proteins were visualized from young LEC rats without signs of hepatitis (Normal $9 w$ rat group). Modification of proteins by HNE may be implicated in oxidative stress-mediated carcinogenesis, since it has been demonstrated that HNE can inhibit some DNA damage repairing enzymes contributing to DNA mutations and genome instability [40].

HNE positivity was not only in the cytoplasm but also around the nuclei. Perinuclear localization of HNE-protein adducts was more intense in the Slight jaundice groups, which is also the group in which potentially cancer-initiated hepatocytes appear. This is the first report showing HNE-modified proteins around the hepatocyte nucleus under hepatitis conditions. Nuclear/perinuclear localization of proteins modified by lipid peroxidation products have been seen in other models and tissues. In vitro, protein adducts to trans-4-hydroxy-2-hexenal (HHE), a product of docosahexaenoic acid oxidation, have been seen around nuclei of neuronal cells treated with HHE [41], while in human biopsies of colon, transitory acrolein-protein adducts distribution around nucleus was associated to the transition from benign into malignant colon tumours [42]. HNE has been shown to react with important signalling proteins such as JNK and various members of the protein kinase $\mathrm{C}$ family [43], suggesting that HNE modifies protein function and hence cellular homeostasis in both physiological and pathological process. One example is the modulation of apoptosis by HNE; while HNE induces apoptosis in procaspase 8-deficient Jurkat cells via the direct interaction of HNE with Fas receptor and the further activation of ASK1 and JNK, HNE also inhibits apoptosis in the same cell line via its adduction to Daxx in the nucleus. HNE binding to Daxx promotes Daxx translocation into the cytoplasm, where it binds to Fas and inhibits apoptosis [44]. This complex modulation of apoptosis by $\mathrm{HNE}$ is dependent of HNE intracellular concentration and shows the wide spectrum of effects of HNE on cellular events. In particular, nuclear localization of HNE-modified proteins opens the door to new insights of the role of HNE in carcinogenesis beyond the already known HNE adduction to DNA [45]. According to the known effect of D-penicillamine to inhibit hepatitis and hepatocarcinogenesis in LEC rats $[46,47]$, D-penicillamine-treated rats showed low levels of ALT, AST and t-bilirubin. Furthermore, D-penicillamine-treated LEC rats presented negative staining for GST-P and HNE-protein adducts, showing that both processes might correlate to copper accumulation and oxidative stress.

In conclusion, our work shows protein modification by lipid peroxidation products as HNE as potential mechanism of cellular disturbances leading to cancer initiation. Nuclear/perinuclear distribution of HNEprotein adducts leads to the hypothesis of a close relationship between lipid peroxidation and hepatocyte initiation that might be mediated by the modification of key proteins rather than the non-specific HNE effect.

\section{Acknowledgement}

This study was supported by the bilateral FrenchCroatian science project COGITO, by the Croatian Ministry of Science, Education and Sports, by COST B35 Action, by the Program Alßan, the European Union Program of High Level Scholarships for Latin America, scholarship No. E04D035320MX, ECOS- 
ANUIES grant M02-S01, CONACYT grant 39525-M and a fellowship from CONACYT AMQ165505.

Declaration of interest: The authors report no conflicts of interest. The authors alone are responsible for the content and writing of the paper.

\section{References}

[1] Vendemiale G, Grattagliano I, Portincasa P, Serviddio G, Palasciamo G, Altomare E. Oxidative stress in symptom-free HCV carriers: relation with ALT flare-up. Eur J Clin Invest 2001;31:54-63.

[2] Nagasaka H, Inoue I, Inui A, Komatsu H, Sogo T, Murayama K, Murakami T, Yorifuji T, Asayama K, Katayama S, Uemoto S, Kobayashi K, Takayanagi M, Fujisawa T, Tsukahara H. Relationship between oxidative stress and antioxidant systems in the liver of patients with Wilson disease: hepatic manifestation in Wilson disease as a consequence of augmented oxidative stress. Pediatr Res 2006;60:472-477.

[3] Seitz HK, Stickel F. Risk factors and mechanisms of hepatocarcinogenesis with special emphasis on alcohol and oxidative stress. Biol Chem 2006;387:349-360.

[4] Wang T, Weinman SA. Causes and consequences of mitochondrial reactive oxygen species generation in hepatitis C. J Gastroenterol Hepatol 2006;21(Suppl 3):S34-S37.

[5] Farber E. Some emerging general principles in the pathogenesis of hepatocellular carcinoma. Cancer Surv 1986;5: 695-718.

[6] Trueba GP, Sanchez GM, Giuliani A. Oxygen free radical and antioxidant defense mechanism in cancer. Front Biosci 2004;9:2029-2044.

[7] Anisimov VN. Biology of aging and cancer. Cancer Control 2007;14:23-31.

[8] Klaunig JE, Kamendulis LM. The role of oxidative stress in carcinogenesis. Annu Rev Pharmacol Toxicol 2004;44: 239-267.

[9] Pitot HC, Dragan YP, Teeguarden J, Hsia S, Campbell H. Quantitation of multistage carcinogenesis in rat liver. Toxicol Pathol 1996;24:119-128.

[10] Dragan YP, Campbell HA, Baker K, Vaughan J, Mass M, Pitot HC. Focal and non-focal hepatic expression of placental glutathione S-transferase in carcinogen-treated rats. Carcinogenesis 1994;15:2587-2591.

[11] Laconi E, Pani P, Farber E. The resistance phenotype in the development and treatment of cancer. Lancet Oncol 2000; $1: 235-241$.

[12] McGlynn KA, London WT. Epidemiology and natural history of hepatocellular carcinoma. Best Pract Res Clin Gastroenterol 2005;19:3-23.

[13] El-Serag HB, Rudolph KL. Hepatocellular carcinoma: epidemiology and molecular carcinogenesis. Gastroenterology 2007;132:2557-2576.

[14] Mori M, Hattori A, Sawaki M, Tsuzuki N, Sawada N, Oyamada M, Sugawara N, Enomoto K. The LEC rat: a model for human hepatitis, liver cancer, and much more. Am J Pathol 1994;144:200-204.

[15] Hayashi M, Miyane K, Hirooka T, Endoh D, Higuchi H, Nagahata H, Nakayama K, Kon Y, Okui T. Inhibitory effects of trientine, a copper-chelating agent, on induction of DNA strand breaks in hepatic cells of Long-Evans Cinnamon rats. Biochim Biophys Acta 2004;1674:312-318.

[16] Jong-Hon K, Togashi Y, Kasai H, Hosokawa M, Takeichi N. Prevention of spontaneous hepatocellular carcinoma in Long-Evans cinnamon rats with hereditary hepatitis by the administration of D-penicillamine. Hepatology 1993;18: 614-620.

[17] Nair J, Strand S, Frank N, Knauft J, Wesch H, Galle PR, Bartsch H. Apoptosis and age-dependant induction of nuclear and mitochondrial etheno-DNA adducts in Long-Evans Cinnamon (LEC) rats: enhanced DNA damage by dietary curcumin upon copper accumulation. Carcinogenesis 2005;26: 1307-1315.

[18] Nair J, Sone H, Nagao M, Barbin A, Bartsch H. Copperdependent formation of miscoding etheno-DNA adducts in the liver of Long Evans cinnamon (LEC) rats developing hereditary hepatitis and hepatocellular carcinoma. Cancer Res 1996;56:1267-1271.

[19] Pradelles P, Grassi J, Maclouf J. Enzyme immunoassays of eicosanoids using acetylcholine esterase as label: an alternative to radioimmunoassay. Anal Chem 1985;57:1170-1173.

[20] Wang Z, Ciabattoni G, Creminon C, Lawson J, Fitzgerald GA, Patrono C, Maclouf J. Immunological characterization of urinary 8-epi-prostaglandin F2 alpha excretion in man. J Pharmacol Exp Ther 1995;275:94-100.

[21] Borovic S, Rabuzin F, Waeg G, Zarkovic N. Enzyme-linked immunosorbent assay for 4-hydroxynonenal-histidine conjugates. Free Radic Res 2006;40:809-820.

[22] Waeg G, Dimsity G, Esterbauer H. Monoclonal antibodies for detection of 4-hydroxynonenal modified proteins. Free Radic Res 1996;25:149-159.

[23] Zarkovic N. 4-hydroxynonenal as a bioactive marker of pathophysiological processes. Mol Aspects Med 2003;24:281-291.

[24] Zivkovic M, Zarkovic K, Skrinjar L, Waeg G, Poljak-Blazi M, Borovic-Sunjic S, Shaur R, Zarkovic N. A new method for detection of HNE-histidine conjugates in rat inflammatory cells. Croat Chem Acta 2005;78:91-98.

[25] Yelisyeyeva O, Cherkas A, Zarkovic K, Semen K, Kaminskyy D, Waeg G, Zarkovic N. The distribution of 4-hydroxynonenal-modified proteins in gastric mucosa of duodenal peptic ulcer patients. Free Radic Res 2008;42:205-211.

[26] Gveric-Ahmetasevic S, Sunjic SB, Skala H, Andrisic L, Stroser M, Zarkovic K, Skrablin S, Tatzber F, Cipak A, Jaganjac M, Waeg G, Gveric T, Zarkovic N. Oxidative stress in small-forgestational age (SGA) term newborns and their mothers. Free Radic Res 2009;43:376-384.

[27] Rutenburg AM, Kim H, Fischbein JW, Hanker JS, Wasserkrug HL, Seligman AM. Histochemical and ultrastructural demonstration of gamma-glutamyl transpeptidase activity. J Histochem Cytochem 1969;17:517-526.

[28] Marquez-Quinones A, Paris A, Roussel B, Perez-Carreon J, Le Berre V, Francois JM, Villa-Trevino S, Gueraud F. Proteasome activity deregulation in LEC rat hepatitis: following the insights of transcriptomic analysis. Omics 2007;11:367-384.

[29] Kasai N, Osanai T, Miyoshi I, Kamimura E, Yoshida MC, Dempo K. Clinico-pathological studies of LEC rats with hereditary hepatitis and hepatoma in the acute phase of hepatitis. Lab Anim Sci 1990;40:502-505.

[30] Sawaki M, Enomoto K, Takahashi H, Nakajima Y, Mori M. Phenotype of preneoplastic and neoplastic liver lesions during spontaneous liver carcinogenesis of LEC rats. Carcinogenesis 1990;11:1857-1861.

[31] Jain S, Suzuki K, Jain S, Sugiyama T, Taniguchi N. Hypomethilation-associated expression of cytochrome P-450 and $\gamma$-glutamyl transpeptidase during hereditary hepatocarcinogenesis in LEC rats. In: Taniguchi N, editor. The LEC rat. New York: Springer-Verlag; 1992. p. 162-168.

[32] Yamada J, Tomiyama H, Yambe M, Koji Y, Motobe K, Shiina K, Yamamoto Y, Yamashina A. Elevated serum levels of alanine aminotransferase and gamma glutamyltransferase are markers of inflammation and oxidative stress independent of the metabolic syndrome. Atherosclerosis 2006;189: 198-205. 
[33] Paolicchi A, Marchi S, Petruccelli S, Ciancia E, Malvaldi G, Pompella A. Gamma-glutamyltransferase in fine-needle liver biopsies of subjects with chronic hepatitis C. J Viral Hepat 2005;12:269-273.

[34] Aliya S, Reddanna P, Thyagaraju K. Does glutathione S-transferase Pi (GST-Pi) a marker protein for cancer? Mol Cell Biochem 2003;253:319-327.

[35] Satoh K, Kitahara A, Soma Y, Inaba Y, Hatayama I, Sato K. Purification, induction, and distribution of placental glutathione transferase: a new marker enzyme for preneoplastic cells in the rat chemical hepatocarcinogenesis. Proc Natl Acad Sci USA 1985;82:3964-3968.

[36] Sakai M, Muramatsu M. Regulation of glutathione transferase P: a tumor marker of hepatocarcinogenesis. Biochem Biophys Res Commun 2007;357:575-578.

[37] Fukuda A, Nakamura Y, Ohigashi H, Osawa T, Uchida K. Cellular response to the redox active lipid peroxidation products: induction of glutathione S-transferase P by 4-hydroxy2-nonenal. Biochem Biophys Res Commun 1997;236: 505-509.

[38] Siems W, Grune T. Intracellular metabolism of 4-hydroxynonenal. Mol Aspects Med 2003;24:167-175.

[39] Poli G, Biasi F, Leonarduzzi G. 4-Hydroxynonenal-protein adducts: a reliable biomarker of lipid oxidation in liver diseases. Mol Aspects Med 2008;29:67-71.

[40] Feng Z, Hu W, Tang MS. Trans-4-hydroxy-2-nonenal inhibits nucleotide excision repair in human cells: a possible mechanism for lipid peroxidation-induced carcinogenesis. Proc Natl Acad Sci USA 2004;101:8598-8602.

This paper was first published online on Early Onilne on 21 October 2009.
[41] Long EK, Murphy TC, Leiphon LJ, Watt J, Morrow JD, Milne GL, Howard JR, Picklo MJ, Sr. Trans-4-hydroxy-2-hexenal is a neurotoxic product of docosahexaenoic $(22: 6 ; n-3)$ acid oxidation. J Neurochem 2008;105:714-724.

[42] Zarkovic K, Uchida K, Kolenc D, Hlupic L, Zarkovic N. Tissue distribution of lipid peroxidation product acrolein in human colon carcinogenesis. Free Radic Res 2006;40:543-552.

[43] Parola M, Robino G, Marra F, Pinzani M, Bellomo G, Leonarduzzi G, Chiarugi P, Camandola S, Poli G, Waeg G, Gentilini P, Dianzani MU. HNE interacts directly with JNK isoforms in human hepatic stellate cells. J Clin Invest 1998;102:1942-1950.

[44] Sharma R, Sharma A, Dwivedi S, Zimniak P, Awasthi S, Awasthi YC. 4-Hydroxynonenal self-limits fas-mediated DISC-independent apoptosis by promoting export of Daxx from the nucleus to the cytosol and its binding to Fas. Biochemistry 2008;47:143-156.

[45] Wacker M, Schuler D, Wanek P, Eder E. Development of a (32)P-postlabeling method for the detection of $1, \mathrm{~N}(2)$-propanodeoxyguanosine adducts of trans-4-hydroxy-2-nonenal in vivo. Chem Res Toxicol 2000;13:1165-1173.

[46] Togashi Y, Li Y, Kang JH, Takeichi N, Fujioka Y, Nagashima $\mathrm{K}$, Kobayashi H. D-penicillamine prevents the development of hepatitis in Long-Evans Cinnamon rats with abnormal copper metabolism. Hepatology 1992;15:82-87.

[47] Klein D, Lichtmannegger J, Heinzmann U, Summer KH. Dissolution of copper-rich granules in hepatic lysosomes by D-penicillamine prevents the development of fulminant hepatitis in Long-Evans cinnamon rats. J Hepatol 2000;32:193-201. 